\title{
System of Rational Decision Making in the Textile Industry of Kazakhstan
}

\section{Aimen Anuarbek Talkayevich*, Atasheva Darya, Khazhgalieva Dina, Kaldygozova Meruert, Zakirova Zarina}

Faculty of Technology, M. Kh. Dulaty Taraz Regional University, Taraz, Republic of Kazakhstan

\section{Email address:}

aimenov_111@mail.ru(A. A. Talkayevich), datasheva07@mail.ru(A. Darya),dina-mx@mail.ru(K. Dina),

meruert-75@mail.ru(K. Meruert)

${ }^{*}$ Corresponding author

\section{To cite this article:}

Aimen Anuarbek Talkayevich, Atasheva Darya, Khazhgalieva Dina, Kaldygozova Meruert, Zakirova Zarina. System of Rational Decision Making in the Textile Industry of Kazakhstan. American Journal of Mechanical and Industrial Engineering. Vol. 6, No. 5, 2021, pp. 62-68. doi: 10.11648/j.ajmie.20210605.12

Received: August 4, 2021; Accepted: August 19, 2021; Published: September 13, 2021

\begin{abstract}
The purpose of the work is to build a digital system of the textile industry of Kazakhstan, taking into account the influence of the production function of value-added on the prices of commercial products of this industry. To achieve this goal, the following tasks are being solved: the formation of industrial policy at the current stage of the scientific and technological process; models of added value in integration processes; the European research project of digitalization. The formation of industrial policy is impossible without establishing relationships between subjects and requires the creation or change of institutions that determine the rights of economic agents and form incentives for their economically active behavior. Industrial clusters are one of the forms of associations that allow reconciling the conflicting interests of economic entities. In each country with competitive clusters, their formation and development took into account the specific socio-economic, geographical, and political characteristics of the territories. In this regard, when assessing the possibility of using the cluster approach in the regions of Kazakhstan, it is necessary to identify positive and negative factors for its implementation. The analysis of the textile production enterprises data for several years has shown that there are real opportunities to restore the prestige of the textile industry of Kazakhstan for the production of demanded volumes of the studied industry. And if we take the necessary measures to increase the volume of export products, then, accordingly, it will lead to a decrease in the volume of imported products. Consortia of RK producers have become one of the forms of implementation of the principle. The newest system promotes the development of small and medium-sized businesses, the creation of domestic industries with high added value. The real way to solve these issues is to increase the Kazakh content in the procurement of national companies and holdings, multinational companies operating in Kazakhstan.
\end{abstract}

Keywords: Cluster, Industrial Policy, Textile Production, Innovative Development, Industrial Innovation Policy

\section{Introduction}

The general scheme of measures for the innovative industrial policy formation can be outlined as follows:

1. a noticeable strengthening of the state role is necessary not only as an organizer and coordinator, but also as a source of funding for R\&D;

2. business climate creation in which the scientific and innovative activity of domestic producers can develop favorably;
3. encouraging the development and commercialization of the results of research and innovation activities;

4. promoting the integration of science, education, production and the market;

5. improvement of the contractual system of financing science;

6. forming a full-fledged macroeconomic infrastructure for the activities of all entities;

7. active support for the science-intensive products export of domestic manufacturers;

8. coordination of innovative development of regions; 
9. system creation for determining the country's scientific and technical priorities;

10. complexes organization (holdings, corporations, consortia, business groups) covering the entire product chain: from scientific development, design through production to sales, service and disposal;

11. improvement of the institutional environment;

12. a new level transition of cooperation between the state and business, including in the form of the conclusion of "industry agreements".

The interaction model between business entities can be presented on the basis of the above in the process of forming and implementing an innovative industrial policy. The model is "the sum", or "system", of our concepts and the connections that we establish between them. In addition, the model also means an abstract image that reflects the main features of the described phenomenon.

The industrial policy formation is impossible without establishing interconnections between the subjects and requires the creation or change of institutions that determine the rights of economic agents and form the incentives for their economically active behavior. Industrial clusters are one of the forms of associations that make it possible to reconcile the conflicting interests of economic entities.

The clusters advantages are as follows [1]:

1. the concentration of rivals, their buyers and suppliers contributes to the growth of effective production specialization;

2. the cluster approach allows for a dialogue between representatives of the business sector and the state, stimulates the creation of new forms of pooling knowledge;

3. being generally accepted in the most developed industrial countries, it contributes to the achievement of greater mutual understanding with world business leaders.

\section{Methods}

A significant number of cluster definitions are available in the economic literature, which is the basis of the cluster theory of economic development. So, M. Porter understands a cluster as a group of geographically adjacent interconnected companies (suppliers, manufacturers, etc.) and related organizations (educational institutions, government bodies, infrastructure companies) operating in a particular area and complementing each other [2]. T. V. Tsikhan identifies three broad definitions of clusters: regionally limited forms of economic activity within related sectors, usually tied to certain institutions (research institutes, universities, etc.); vertical production chains; rather narrowly defined sectors in which the adjacent stages of the production process (for example, the chain "supplier - manufacturer - retailer customer"); industries identified at a high level of aggregation (for example, a "chemical cluster") or a set of sectors at an even higher level of aggregation (for example, an "agro-industrial cluster") [3].
Let's highlight the following essential features of the cluster:

1. the presence of leading firms capable of having a significant share in the domestic and foreign markets, supplemented by specialized service organizations;

2. concentration of cluster members in a limited area that presents unique advantages;

3. interaction of cluster members with each other in order to produce products that are competitive in the domestic and foreign markets;

4. the presence of competition between cluster members;

5. accelerated dissemination of innovations due to the developed information transmission network.

Thus, the cluster approach is the basis for a constructive dialogue between representatives of the business sector and government authorities on the development of science and production, attracting investments, and ensuring the necessary measures to solve them.

The key success factors in the development and implementation of cluster development strategies are:

1) Formation of a socially responsible position of business leaders;

2) The development of partnerships among various business groups, and the main tool for their implementation is framework agreements.

In each country with competitive clusters, specific socioeconomic, geographical, and political characteristics of the territories were taken into account in their formation and development. In that regard, when assessing the possibility of using the cluster approach in the regions of Kazakhstan, it is necessary to highlight the positive and negative factors for its implementation.

Positive factors for the clusters development in Kazakhstan are:

1. the extensive experience presence in the formation and development of territorial-production complexes and various forms of cooperation;

2. a high level of intellectual potential;

3. the development of technological infrastructure and technological culture, etc.

The factors constraining the clusters development are: weak ties between research institutions and business; inconsistency of educational programs of educational institutions with the needs of clusters; poor quality of the business climate and low efficiency of industry associations; insufficiently high level of trust between representatives of business, science, government, etc.

Thus, the industrial cluster formation will allow restoring the broken relationships between economic entities, and will also serve as the basis for the development of an effective model of innovation and industrial policy.

In the textile industry, the cost added chain (VAC) is divided into 5 main stages (links). The first stage is the most labor-intensive and includes the production of raw materials (growing raw cotton). There is no synthetic fiber production in Kazakhstan. The raw material production process also includes the primary refining of raw cotton and the 
production of cotton fiber. In Kazakhstan, it is not yet possible to talk about complete VAC in textile production, since at the stage of finishing the fabric, the chain breaks and further, in the production of textiles for final consumption and clothing, imported source material is already used. Only one enterprise currently operates in the production of harsh fabric - South Textiline KZ LLP. In 2015, the previously idle factory of UTEKS KZ JSC was launched [4].

Determination of sectoral priorities for Kazakhstan's participation in global cost chains is based on the analysis of national policy documents. The main emphasis is placed on the State Program of Industrial and Innovative Development of the Republic of Kazakhstan for 2015-2019. The program is a logical continuation of SPFIID-2014 and takes into account the experience of its implementation.

For that task, we can stop at the understanding that it is nevertheless necessary to keep in mind the adjustment of the main directions of industrial cooperation (ONPS), taking into account the assessments of the cooperative potential of priority industries and sectors. The ONPS projects introduced through the EEC are not completed documents for adoption by the EAEU member states, in particular the Kazakhstani side, and in that regard, they made a number of proposals and comments.

The integration association's creation in the past pursued the goal of only increasing the turnover, and now, through integration, they are trying to create full-fledged industrial and commercial complexes. The industrial complexes creation and production facilities are currently being evaluated from the point of view of integration into global cost chains [5]. That topic has become central in the study of integration processes.

The main focus is on the State Program of Industrial and Innovative Development of the Republic of Kazakhstan for 2015-2019. The program is a logical continuation of SPFIID2014 and takes into account the experience of its implementation. As a result of the analysis, it became known that one of the most important conditions for the development of industrial production in Kazakhstan is integration into the production chains of world manufacturers of finished products. At the same time, the main factor in the development of industrial production in Kazakhstan is access to a large and growing sales market for industrial products of the Customs Union, as well as cost advantages of Kazakhstan as an assembly site for foreign companies relative to other $\mathrm{CU}$ countries. In textile production, CDS is divided into 5 main stages (links). The first stage is the most labor-intensive and includes the production of raw materials (growing raw cotton). There is no synthetic fiber production in Kazakhstan. The raw material production process also includes the primary refining of raw cotton and the production of cotton fiber.

\section{Result}

In Kazakhstan, it is not yet possible to talk about complete VAC in the textile industry, since at the stage of finishing the fabric, the chain is broken and further, in the production of textiles for final consumption and clothing, imported source material is already used. Only one enterprise currently operates in the production of harsh fabric - South Textiline KZ LLP. In 2015, the previously idle factory of UTEKS KZ JSC was launched. A bet has been placed on the sale of finished textile products. Uzbekistan refused to export raw cotton and relies on the sale of finished textile products. The competitiveness of the industry in the country is going to increase, including through contract manufacturing, there are already agreements that Uzbekistan will sew clothes for the HugoBoss brand. The clothing production in cost terms increased by 3.6 billion tenge, or $18 \%$, over the five months of that year in comparison with the previous one. According to the light industry representatives, the positive dynamics was influenced not by the increase in production, but by the rise in the cost of imported raw materials and, accordingly, the cost of goods, the correspondent of the Kapital. kz business information center reports [6]. According to ranking. kz data, Kazakhstani manufacturers began to produce less women's and men's outerwear by $25.6 \%$ and $23.8 \%$, respectively. They gave way to knitted, fur and hosiery products, the production of which in physical terms increased from 2 to 3.4 times. At the same time, prices for men's clothing in stores in the country's markets increased from $4.8 \%$ to $8.7 \%$, women's and children's clothing - from $5.1 \%$ to $12.8 \%$.

Over the past two decades, there have been significant changes in the industry, which were aimed at changing approaches to managing the industry, displacing global production centers and sales markets. These industry transformations were the result of a number of phenomena: economic shift in producer countries; capital growth and an increase in the level of technological development; abolition of quotas and regulation of the industry according to standard WTO rules; crisis phenomena in the economy and a decrease in consumer activity; strengthening of consumer requirements for quality [7].

Also, a significant change in the structure of light industry in recent years is the transfer of the global production centers of the industry from Europe and the United States to developing countries. Today, $70 \%$ of clothing world exports and textiles go to the countries of Southeast Asia, Turkey, Latin America. It is worth noting the leading role of China, which exports more than $30 \%$ of manufactured products, while the USA, Germany, France and Japan, which were previously considered the leaders of the light industry, are now the main importers of light industry products. Consumption in these countries exceeds $50 \%$ of the global consumption of clothing and textiles. Along with the economy of the leading sectors of the country, the textile industry is far from a leading position. Today in Kazakhstan, the share of textile and clothing production is no more than $0.2 \%$ in the total manufacturing industry [8].

L. Khudova, President of the Association of Light Industry Enterprises, emphasizes the dependence of domestic manufacturers on the cost of imported raw materials: "Today 
in Kazakhstan all workshops and sewing companies import $100 \%$ of woolen and worsted fabrics necessary for the production of school uniforms, women's and men's suits, coats and uniforms, volume". At the same time, Kazakhstan is quite capable of satisfying the need for these types of fabric on its own. But for that it is necessary to create a cost chain: from collecting, for example, wool from farmers, to processing enterprises, and then to a clothing manufacturer. Moreover, these fabrics have export potential and are always in demand both within the country and abroad. «The project for the worsted and woolen fabrics production, according to L. Khudova will cost about 30 million euro. Domestic small and medium-sized businesses do not have sufficient collateral to launch a project of that scale on their own. Today in the country we can find organizations that are engaged only in the first stage of processing - wool washing. "To create the entire cost added chain, it is necessary to draw the attention of the state to the problem, at least in the format of publicprivate partnership". For example, the development of light industry in Uzbekistan today is going at an enviable pace for us. Large-scale and significant enterprises for the industry are built under the guarantee of the state. In addition, the country's authorities have canceled VAT on imported raw materials and materials for clothing manufacturers. Kazakhstani sewing companies, in order to sew a jacket or coat, have to pay customs duties and all types of taxes. That increases the cost of domestic products and makes them uncompetitive in comparison with goods that are semilegally or completely illegally imported from Uzbekistan.

Since the beginning of 2000 , positive tendencies in the light industry of Kazakhstan gradually began to appear. That was facilitated by the state support of small business, which began in those years, as a result of which more than $80 \%$ of enterprises in the industry became small and medium-sized businesses, while they were equipped with outdated equipment, the load of which was $40 \%$ [9].

In the production structure, along with the production of textiles, clothing, footwear, knitwear, hosiery and fur products, hats, there was a high share of the production of cotton fiber, clothing for government agencies. The light industry began to meet the needs of the population in medical clothing, as well as in special, work clothing and footwear, and in personal protective equipment.

But that progress could not push the industry forward and therefore the share of Kazakhstan in the world market of textiles, clothing and knitwear remained very low. The domestic market was also formed by imports, shuttle traders or smuggling. In consumer of the light industry goods, the share of domestic products did not exceed $8 \%$ [10].

The Ministry of Industry and Infrastructure Development of the country claims that more than 50 events are planned in the country to solve systemic problems. They are aimed at creating a full-fledged cost chain and increasing production. Priority problems include providing textiles with raw materials, combating illegal trade in products, increasing local content and increasing competitiveness. "Measures are also envisaged to attract investments in these sectors for the implementation of projects using advanced technologies". In 2019 , it is planned to commission 4 new projects for a total amount of 5 billion tenge, the ministry said in an official statement.

In general, according to MIIR (in January-June 2019), Kazakhstan manufacturers still retain the market for defense orders and work wear, which provide manufacturers with guaranteed sales and minimal risk of unclaimed products. The volume index (PVI) of textiles was $120.5 \%$, clothing $108.4 \%$, and leather and related products $-97.2 \%$. Growth is noted in the production of textiles and clothing due to an increase in the production of cotton fiber, finished textiles, and outerwear. In the production of leather and related products, there is a decline due to a decrease in the production of footwear.

Statistical data analysis on the production volume of light industry products shows the dynamics of the reduction of its share in the total volume of industry in Kazakhstan. The declining share of the industry is caused by such problems as the lack of modern technologies (hence the low quality of products), low labor productivity, a reduction in the raw material base, and weak marketing. The reduction in the raw material base is associated with a decrease in the number of cattle, sheep and goats. Moreover, a significant amount of the wool produced is imported abroad. We can say that in recent years the light industry of Kazakhstan, where imports exceed exports, has practically ceased to exist. Production volumes have decreased so much that they can be equated with one large enterprise, while the country's demand for the products of that industry is very high [11]. However, representatives of the textile industry cite as an example measures to support the sector in neighboring countries, emphasizing that they are the most desirable for domestic producers. For example, in Belarus there is a legislative obligation to provide at least $30 \%$ of the area in shopping centers in the country for local sewing companies. The Russian authorities are moving towards the same decision, gradually providing their sewing shops with shelves in the shopping center. In addition, the country's authorities have introduced a 50\% VAT subsidy for school uniforms. The relaxation works if it is made from a fabric of a domestic manufacturer. All enterprises of the textile industry in Kyrgyzstan are exempt from all types of taxes. They pay a minimum wage per sewing unit and work under a patent, regardless of the number of employees in the company. Turkey, whose clothing occupies the lion's share of the Kazakhstan market, subsidizes the lease of retail space for national brands in Kazakhstan shopping centers.

\section{Discussion}

Rapid capital turnover, steady growth, low need for finance are all invariable properties of light industry, which makes it prevalent in countries with developed and developing economies. Analyzing the experience of that industry development in other countries, we can note the active support of the state, which is expressed in the provision of certain tax incentives, attracting investment 
capital, and promoting the promotion of products intended for export. In the total structure of industrial production in such developed countries as the USA, Germany, France, Italy, the specific weight of the textile industry is about 6$10 \%$, and in Japan and Korea it is second only to the automotive industry in the structure of marketable products. Thanks to significant government support in China, Turkey, India, over the past twenty years, the center of the textile industry has shifted to South America and Asia, which caused a rapid flourishing of that industry [12].

The government is concerned with the development of small and medium-sized businesses, the creation of domestic industries with high added cost. And one of the ways to solve these issues is to increase the Kazakh content in purchases of national companies and holdings, transnational companies operating in Kazakhstan. Back in 2005, seven pilot industrial and service clusters were identified, including the textile industry. Thanks to that, from 2008 to 2018 , the volume of textile production increased 3.6 times. The growth is due to the commissioning of 49 enterprises of the textile industry at the expense of investments in the amount of 74.6 billion tenge. As a result, more than 6 thousand jobs have been created. Consortia of manufacturers have become one of the forms of implementation of the cluster principle [13].

In the textile industry, a successful model example of cluster development is the Zhasampaz consortium, which currently includes 57 manufacturing enterprises. The Zhasampaz consortium has combined all the links of the production process: from the cultivation and processing of raw cotton to the production of finished products, bringing the share of local content in the state defense order to $60 \%$. In accordance with the investment agreement, the enterprises participating in the consortium in 2018 invested more than 5 billion tenge in the creation of new and modernization of existing production facilities. Tax revenues to the budget from the consortium members exceeded 3 billion tenge. One of the successful enterprises of the consortium is AzalaTextile LLP, located in Shymkent. According to the deputy director of AzalaTextile Bakytzhan Abekova, the enterprise has a full production cycle from raw cotton to finished products. Raw materials are $100 \%$ Kazakh. Moreover, $80 \%$ of the yarn produced from raw materials is processed at our own production; the remaining $20 \%$ is exported abroad. Now "AzalaTextile" produces ready-made fabrics, bed linen, terry products [14]. Weaving production produces 14 million running meters of harsh fabric per year, spinning production - 6,800 tons of yarn per year. The enterprise is equipped with highperformance automated sewing equipment, which makes it possible to produce high-quality bed linen, terry towels from its own raw materials. But it is more profitable for the enterprise to "sew" Turkish brands.

The iMAIN project is a European research project led by the Fraunhofer Institute, funded by the European Union, aimed at developing a new decision-making system for preventive maintenance. The envisaged maintenance system integrates embedded information devices and artificial intelligence tools to extract knowledge with the latest practices of uptime and operational reliability [15]. The resulting solution will provide enhanced capabilities beyond what is achievable with current maintenance best practices. The results will be: increased system life cycle of process equipment; reduced maintenance costs; increasing the reliability of the entire process.

In the iMAIN project of the Seventh EU Framework Program (Smart Maintenance), eight partners from four European countries are collaborating to develop the necessary IT infrastructure, specific sensors and embedded processing devices, and special algorithms and models. The results and solutions have already been successfully demonstrated in sheet metal stamping technologies (Figure 1).
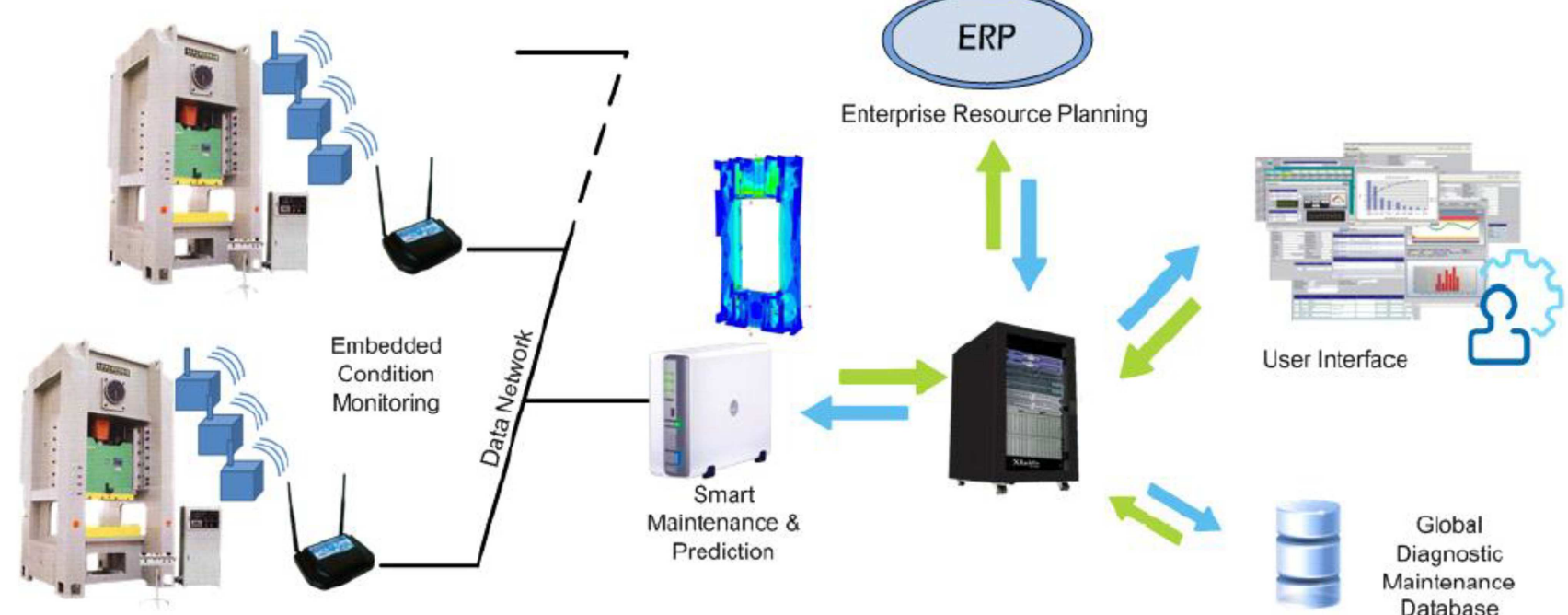

Predictive maintenance concept

Source: Fraunhofer Institute (2016)

Figure 1. Project iMAIN - The latest decision-making system for smart maintenance. 


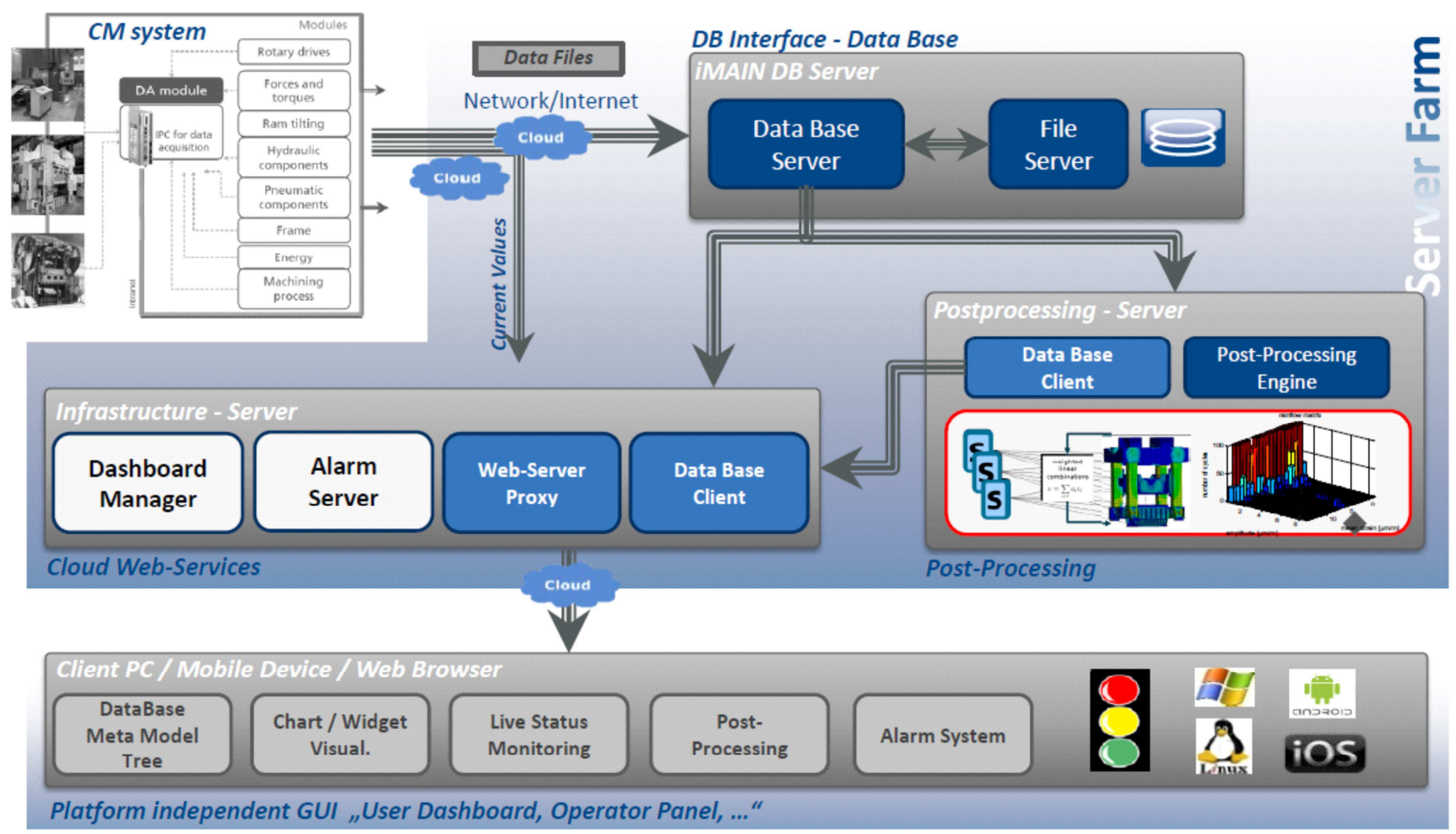

Source: Fraunhofer Institutes (2016).

Figure 2. Machine learning approach with iMAIN solution.

A multidisciplinary approach to achieving in-depth knowledge of material properties and parts life is reflected in a broad instrumentation and data acquisition strategy. A "multidomain" approach was developed to deal with different volumes and types of data. That unified approach to maintenance creates new service-oriented business models (Figure 2). The model is "the sum", or "system", of our concepts and the connections that we establish between them. In addition, the model also means an abstract image that reflects the main features of the described phenomenon (Figure 2).

The iMAIN project is a European research project led by the Fraunhofer Institute, funded by the European Union, aimed at developing a new decision-making system for maintenance. The envisaged maintenance system integrates embedded information devices and artificial intelligence tools to extract knowledge.

\section{Conclusions and Suggestions}

1. Analysis of data enterprises for the textiles production for a number of years showed that there are real opportunities to restore the prestige of the textile industry of Kazakhstan for the production of the demanded volumes of the studied industry.

2. Measures are needed to increase the volume of export products and, accordingly, to reduce the volume of imported products. Consortia of Kazakhstani producers have become one of the forms of implementing the cluster principle.

3. The newest system contributes to the development of small and medium-sized businesses, the creation of domestic industries with high added cost. The real way to solve these issues is to increase the local content in the procurement of national companies and holdings, transnational companies operating in Kazakhstan.

4. In the textile industry, there are models of cluster development in the form of consortia, enterprises have a full production cycle - from raw cotton to finished products, and domestic brands are created.

5. The iMAIN Project was developed - a European research project led by the Fraunhofer Institute, funded by the European Union and aimed at developing a new decision-making system, new service-oriented business models are working.

\section{References}

[1] Association of light industry enterprises of Kazakhstan. Astana, 2012.

[2] Baizakov S., Baizakov N. The problem of a three-structure economy and the use of its model for comparing the rates of development of countries-strategic partners of Kazakhstan / Economy and statistics №. 2 2018, p. 25-29.

[3] On approval of the state program "Digital Kazakhstan". Kazakhstan Pravda, 12. 07. 2018.

[4] A. Aimen, D. Atasheva, I. Suleimenova, A. Moldasheva. The state and ways of development of light industry in Kazakhstan. Scientific periodical journal "Izvestiya vuzov. Russia, Technology of the textile industry "№. 2, 2020, p. 36-41. 
[5] Report of the Association of light industry of Kazakhstan within the grant program of the project of the US Agency for international development (USAID), on international development to improve the business environment "Research of small and medium-sized businesses in the light industry sector of Kazakhstan "June 2010. p. 7.

[6] A. Aimen, D. Atasheva, D. Khazhgalieva, L. MyrzakhmetSarykulova, A. Dusebaeva. Import substitution problems in light industry. Scientific periodical journal- Izvestiya vuzov. Russia, Technology of the textile industry №. 2, 2020, p. 42-47.

[7] A. Aimen, D. Atasheva, D. Khazhgalieva, G. Amirova, I. Suleimenova. Experience of foreign countries in the development of light industry. Scientific periodical journal "Izvestiya vuzov. Russia, Technology of the textile industry "№. 2, 2020, p. 57-59.

[8] iMain - A Novel Decision Support System for Intelligent Maintenance in Forming Presses.www.iwu.fraunhofer.de.

[9] A. Aimen, I. Suleimenova. Assessment of the competitive positions of the Zhambyl region of the Republic of Kazakhstan in the context of the globalization of the world economy. Quarterly scientific and information journal "Economics and Statistics", №. 1, 2021, p. 182-191.

[10] Report of the Association of Light Industry of Kazakhstan within the framework of the grant program of the SShA International Development Agency (USAID) project on international development to improve the business environment Research of problems of small and medium-sized businesses in the light industry sector of the Republic of Kazakhstan-. - 2016, June. p. 7.
[11] M. G. BALYKHIN, L. V. NEFEDOVA, A. V. GENERALOVA. VALUE ANALYSIS IN THE MANAGEMENT OF ENTERPRISES OF LIGHT INDUSTRY. Scientific periodical journal "Izvestiya vuzov. Russia, Technology of the textile industry "№. 2, 2017, p. 917.

[12] Experience and prospects of using functional and cost analysis [Electronic resource] - Access mode - URL: http://economylit.online/ predprini-matelstvobiznes 728/opyit-perspektivyi-ispolzova-niya-funktsionalno26595.html

[13] V. M. Sheravner. Development of the methodology of functional and cost analysis of commercial organizations: Kan. dis. ekon. nauk. - Rostov-on-Don, 2006.; [Electronic resource] - Access mode. - URL: Scientific library of dissertations and abstracts disserCat. http://www.dissercat.com/content/razvitie-metodikifunktsionalno-stoimostnogo-analiza-kommercheskikhorganizatsii\#ixzz5GEV2wBxA

[14] S. Yu. Chernoglazkin, M. G. Balyhin. Pushina L. A., Movsumzade E. M. Light industry in national production//History and pedagogy of natural science - 2016, No 2. p. 17-20.

[15] A. V. Kravchenko, A. V Generalova. Modern problems of the development of the domestic real sector of the economy//Scientific and methodological journal Concert. 2016. 15. p. 801-805. 